\title{
EVALUATION OF ANTIMICROBIAL EFFECTIVENESS OF ENDOVAC AND LASER FOR TREATMENT OF INFECTED PERMANENT ROOT CANALS
}

\author{
Amira Safwat Alghazaly* and Walaa Ahmed Alshareef **
}

\begin{abstract}
Present study was conducted with the aim of evaluating antimicrobial efficacy of two activation irrigating techniques namely; (Nd:YAG) laser and EndoVac with 5.25\% sodium hypochlorite, against biofilm of two types of microbial strain, Candida albicans (ATCC 14053) and Enterococcus faecalis (ATCC 19433). In total, the root canals of 40 extracted single-rooted human mandibular premolar teeth were prepared using the ProTaper Next system rotary instrument up to X4 (\# 40). Samples were divided randomly in 8 groups ( $n=5$ each). Negative group teeth were checked for their sterility. Then, the remaining teeth were inoculated with Enterococcus faecalis and Candida albicans and incubated at $37^{\circ} \mathrm{C}$ for 48 hours to isolate the bacteria. Then the new strains were cultured and adjusted at $10^{6}-10^{8} \mathrm{CFU} / \mathrm{mL}$ according to $0.5 \mathrm{MacFarland}$ standard using a spectrophotometer at an optical density $\left(\mathrm{OD}_{595}\right)$. After three weeks of incubation in respective media for each microbe, the formation of biofilms was evaluated and the $\mathrm{OD}_{595}$ of both $\boldsymbol{E}$. faecalis and Candida albicans were measured by spectrophotometer as a positive control of the test. Then, the remaining samples were irrigated with the designed irrigation technique for each group. Then the turbidity of the growth was determined by Spectrophotometer at $595 \mathrm{~nm}$ of each group. Significant difference was found among all the groups in comparison to the control group. Both irrigation technique showed significant reduction in bacterial counts post-treatment, but the greatest reduction was in the laser treatment of the $\boldsymbol{E}$. faecalis infected group.
\end{abstract}

\section{INTRODUCTION}

Bacteria and their byproducts consider as the main etiological factor for the initiation of pulpoperiapical lesions. Intracanal irrigation is playing a major role for endodontic treatment success as it eliminates microorganisms that escape from the mechanical detriment. Although around 500 species or even more of bacteria have been identified in the oral environment, only a limited number have been found to colonize the root canal system. ${ }^{(1)}$ This suggest that the root canal system is a hostile and difficult environment for microbes to survive, and those that do survive may be difficult to be eliminated. Most infective microbes within the root ca-

\footnotetext{
* Endodontics, Faculty of Dentistry, October 6 University, Giza, Egypt

** Microbiology and Immunity, Faculty of Pharmacy, October 6 University, Giza, Egypt
} 
nal system are bacteria; however, fungi have also been isolated. The microbial flora within necrotic root canals depends on the stage of the infection that exist. Initially, the bacterial load may be facultative (i.e. those that can use dissolved oxygen or chemically derived oxygen for respiration and can live under aerobic or anaerobic conditions), as time progresses (over 3 months) and the consumption of oxygen within the root canal increases, about $90 \%$ of the microbial flora is obligate anaerobic bacteria (those that do not require oxygen to live). ${ }^{(2)}$ Microorganisms can exist within the root canals, dentinal tubules, accessory canals, canal ramifications, apical deltas, fins and transverse anastomoses. They are found within biofilms (structured communities encapsulated within a self-developed polymeric matrix and adherent to the root surface) or in planktonic form (drifting in a body of fluid). Microbes are difficult to culture, and it is known that those within a biofilm are 1000 times more resistant to biocides than the same organisms in planktonic forms. Disinfection of the root canal system, as part of endodontic therapy, by preparation and irrigation is the key in reducing the number of bacteria within the root canal and helping to control periapical disease.

(3) Conventional endodontic therapy using both rotary instrumentation and standard needle irrigation with sodium hypochlorite also shows incomplete removal: According to Molina et al, only $68 \%$ of the root canal surface was debrided with this approach. In addition, this needle irrigation is ineffective at removing hard and soft tissue remnants and debriding the apical third region. ${ }^{(4)}$ This work will therefore compare the antibacterial efficacy of; laser and Endovasc activation systems with sodium hypochlorite, against the most resistant intracanal microorganisms.

\section{MATERIALS AND METHODS}

\section{Samples preparation}

A total of 40 extracted human single rooted mandibular premolar teeth with patent root canals and fully developed root apices, extracted for periodontal or orthodontic reason, were selected for the study. Teeth having cervical caries, cracks in root, immature apex, resorbed roots, and calcified canals were excluded. Each tooth was radio-graphed buccolingually and mesiodistally to confirm the presence of a single patent canal and sectioned below the cementoenamel junction with a diamond disk to obtain a standardized root length of $13 \mathrm{~mm}$. The apical third of the teeth was covered with two coats of nail varnish. The teeth were embedded in polyvinyl siloxane impression material up to their standardized length to facilitate handling. Canal patency was established using $10 \mathrm{~K}$ file and instrumented using ProTaper Next rotary file system (Dentsply Maillefer, Ballaigues, Switzerland) up to an apical size of file X4. A total of $2 \mathrm{ml}$ of $5.25 \%$ $\mathrm{NaOCl}$ was used between each instrument during the procedure for two minutes and $2 \mathrm{ml}$ of $17 \%$ of EDTA (ethylenediaminetetraacetic acid) to remove the smear layer. The irrigating solutions were delivered via a sterile 30-gauge nickel titanium needle, which penetrated to $2 \mathrm{~mm}$ of the working length. The teeth were steam autoclaved at $121^{\circ} \mathrm{C}$, 15 psi for 15 minutes ${ }^{(5,6)}$. Final irrigation was done with $10 \mathrm{ml}$ of $17 \%$ EDTA \& 5.25 of $\mathrm{NaOCl}$, respectively.

\section{Microbiological test}

\section{Biofilm preparation}

The samples were ready for incubation, five teeth in MHB (Muller- Hinton Broth) and the others in SDB (Sabouraud Dextrose Broth) (Merck, Darmstadt, Germany) at $37^{\circ} \mathrm{C}$ overnight to confirm their sterility. Teeth in this negative control group didn't receive any further irrigation. After that, preparing the cultured suspension of $\boldsymbol{E}$. faecalis and Candida albicans for the remaining examined groups was done in two ml Eppendorf of the respective medium (MHB for $\boldsymbol{E}$. faecalis and SDB for Candida albicans) to place the samples 
in it for three weeks. From beginning, the pure bacterial and yeast cultures were incubated at $37^{\circ} \mathrm{C}$ in the presence of $5 \% \mathrm{CO}_{2}$ for bacterial culture and incubated aerobically for yeast culture for 24 hours to isolate the bacteria. Then the new strains were cultured in MHB and SDB, respectively and adjusted at $10^{6}-10^{8} \mathrm{CFU} / \mathrm{mL}$ according to 0.5 MacFarland standard using a spectrophotometer (UV-VISIBLI, Shimadzu, Japan) at an optical density $\left(\mathrm{OD}_{595}\right)$ of one at $595 \mathrm{~nm}$ to confirm the inoculum concentration. After three weeks of incubation in respective media, the formation of biofilms was evaluated and the $\mathrm{OD}_{595}$ of both $\boldsymbol{E}$. faecalis and Candida albicans were measured by spectrophotometer as a positive control of the test.

\section{Teeth inoculation}

The samples were divided and sub-cultured into sterile $50 \mathrm{ml}$ of MHB and $50 \mathrm{ml}$ of SDB into eight groups according to the protocol used:

Group 1: Erlenmeyer flask of $100 \mathrm{ml}$ containing $50 \mathrm{ml}$ of sterile MHB and the five teeth of $\boldsymbol{E}$. faecalis biofilm after laser medication.

Group 2: Erlenmeyer flask of $100 \mathrm{ml}$ containing $50 \mathrm{ml}$ of sterile MHB and the five teeth of $\boldsymbol{E}$. faecalis biofilm after EndoVac medication.

Group 3: Erlenmeyer flask of $100 \mathrm{ml}$ containing $50 \mathrm{ml}$ of sterile SDB and the five teeth of Candida albicans biofilm after laser medication.

Group 4: Erlenmeyer flask of $100 \mathrm{ml}$ containing $50 \mathrm{ml}$ of sterile SDB and the five teeth of Candida albicans biofilm after EndoVac medication.

Group 5: Erlenmeyer flask of $100 \mathrm{ml}$ containing $50 \mathrm{ml}$ of sterile MHB as a negative control, (Five teeth).

Group 6: Erlenmeyer flask of $100 \mathrm{ml}$ containing $50 \mathrm{ml}$ of sterile SDB as a negative control, (Five teeth).
Group 7: Erlenmeyer flask of $100 \mathrm{ml}$ containing $50 \mathrm{ml}$ of $\boldsymbol{E}$. faecalis suspension in MHB adjusted at $10^{8} \mathrm{CFU} / \mathrm{mL}$ as a positive control, (Five teeth).

Group 8: Erlenmeyer flask of $100 \mathrm{ml}$ containing $50 \mathrm{ml}$ of Candida albicans suspension in SDB adjusted at $10^{8} \mathrm{CFU} / \mathrm{mL}$ as a positive control, (Five teeth).

So, after incubation of whole flasks for three weeks, we start to determine the turbidity of the growth by Spectrophotometer at $595 \mathrm{~nm}$ and compare the $\mathrm{OD}_{595}$ of each group with $\mathrm{OD}_{595}$ of the control mentioned above ${ }^{(7)}$

\section{Activation of the irrigant solution}

After the samples get infected by the targeted microbe. Each group was treated as follows:

\section{Nd: YAG Laser group:}

Nd: YAG laser (Fotona) of 1064 wavelength with standard settings of $15 \mathrm{~Hz}$ at $100 \mathrm{ml}=1.5 \mathrm{~W}$ at pulsed mode was repeated four cycles for $5 \mathrm{~s}$ each. A 200U optical fiber $2 \mathrm{~mm}$ short of working length was introduced into root canal without activating laser. Then, laser was activated, and fiber guided in apical to coronal direction with circular movements and in contact with wet root canal walls. During each irradiation, the canals were irrigated with $2 \mathrm{ml}$ of $5.25 \% \mathrm{NaOCl}$ according to the corresponding group. All samples were rinsed with $2 \mathrm{ml}$ of sterile saline to remove the remaining bacteria and $\mathrm{NaOCl}$.

\section{EndoVac/Apical negative pressure group:}

30 seconds period of irrigation with $2 \mathrm{ml}, 5.25 \%$ $\mathrm{NaOCl}$ was done by using the master delivery tip while the macrocannula was constantly moved up and down in the canal. This was followed by leaving the canal full of irrigant for 30s. Three irrigation cycles using the microcannula placed at full working length followed. The first cycle was $30 \mathrm{~s}$ of $2 \mathrm{ml} 5.25 \% \mathrm{NaOCl}$ followed by $30 \mathrm{~s}$ of soaking; the second cycle was $1 \mathrm{~min}$ of $10 \mathrm{ml}, 17 \%$ 
EDTA followed by 1 min of soaking; and the third cycle was $1 \mathrm{~min}$ of $5 \mathrm{ml}, 5.25 \% \mathrm{NaOCl}$ followed by $1 \mathrm{~min}$ of soaking. The protocol is the same that used by Parente Root canal debridement using manual dynamic agitation or open system ${ }^{(8)}$. After disinfection, paper points were used to collect the samples from the teeth and were incubated for three weeks and the turbidity was tested.

\section{RESULTS}

A statistical program (GraphPad Insta, Statistical Package for the Social Sciences 3.10) was used for all analyses. Normality distribution of the variable mean $\mathrm{CFU} / \mathrm{mL}$ of Candida albicans was verified using the ANOVA test (one-way analysis of Variance). $\mathrm{P}$ value is $<0.0001$, considered extremely Significant differences in mean CFU/ mL of Candida albicans and $\boldsymbol{E}$. feacalis amongst groups were assessed by the Tukey- Kramer Multiple comparison. The significance level was set at 5\%.

Data obtained for each irrigation regimen are showed that both techniques were able to significantly reduce the bacterial number in the root canal after 21 days collection.

The distribution of the baseline means counts of Candida albicans and E. feacalis in the teeth of the two therapeutic techniques is depicted in Figure (1\&2), respectively. The extremely significant differences in mean counts were detected among group ( $p>0.0001$, Tukey- Kramer Multiple comparison test).

The laser assisted group had been shown significantly reduction in both species' biofilms. Moreover, the significant reduction in Candida albicans levels was $73.65 \%$ in the EndoVac system while $72 \%$ in the Laser system as shown in Figure (3). EndoVac system significantly decreases the growth of both Candida albicans and E. feacalis, but its effect on the latter was significantly lower (only $53.10 \%$ ) than in Laser group (88\%) as shown in Figure (3, 4 and 5).

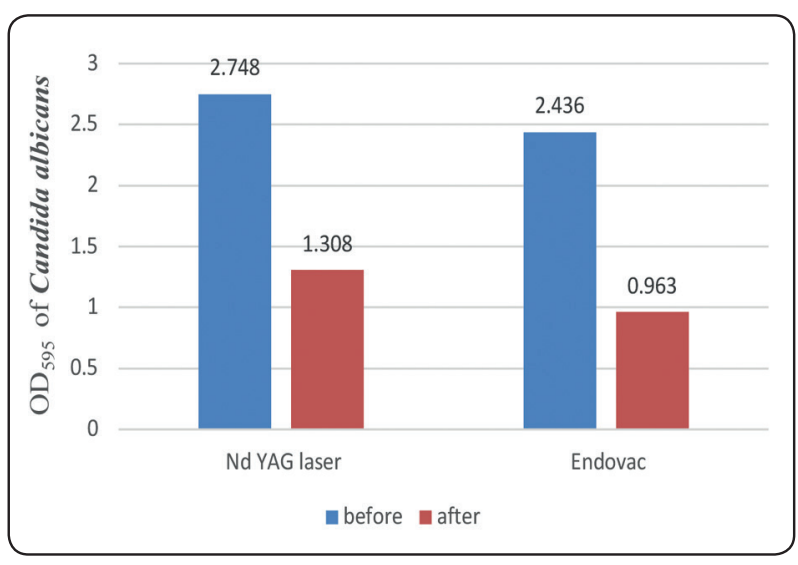

Fig. (1) Evaluation of biofilm of Candida albicans before and after medication

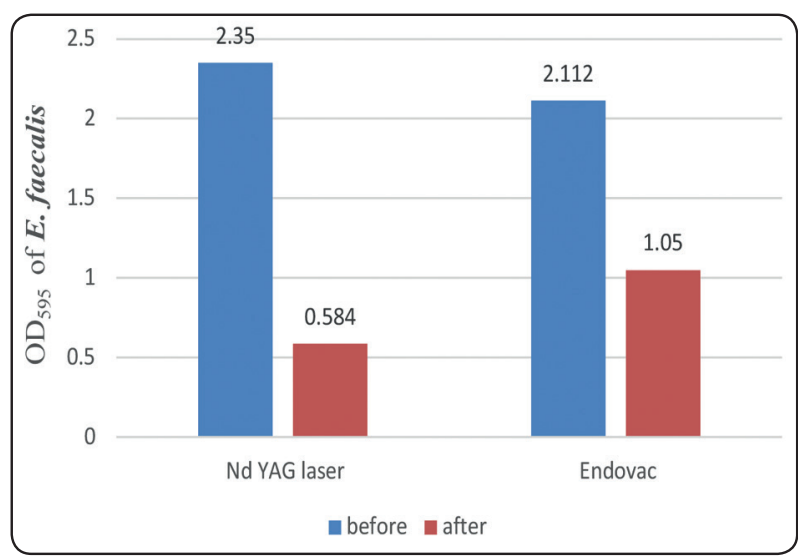

Fig. (2) Evaluation of biofilm of $\boldsymbol{E}$. faecalis before and after medication

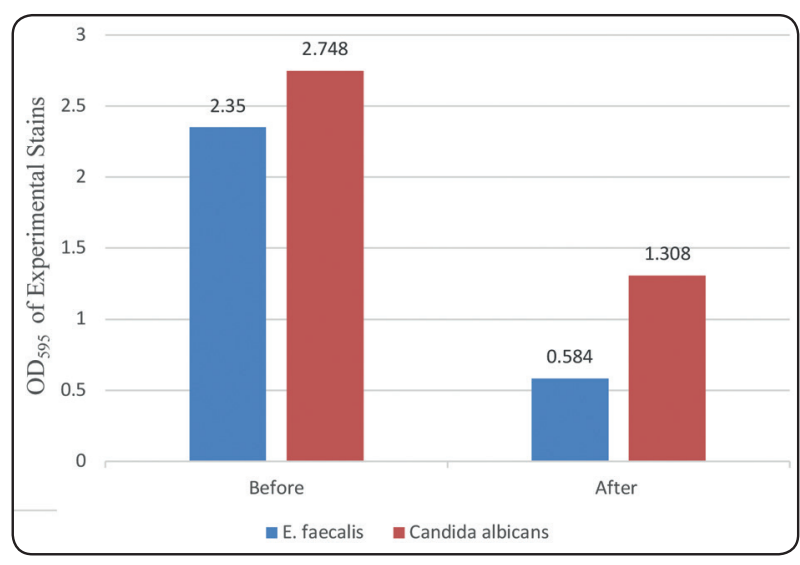

Fig. (3) Comparison of biofilm of each E. faecalis and Candida albicans before and after medication by Nd YAG laser 


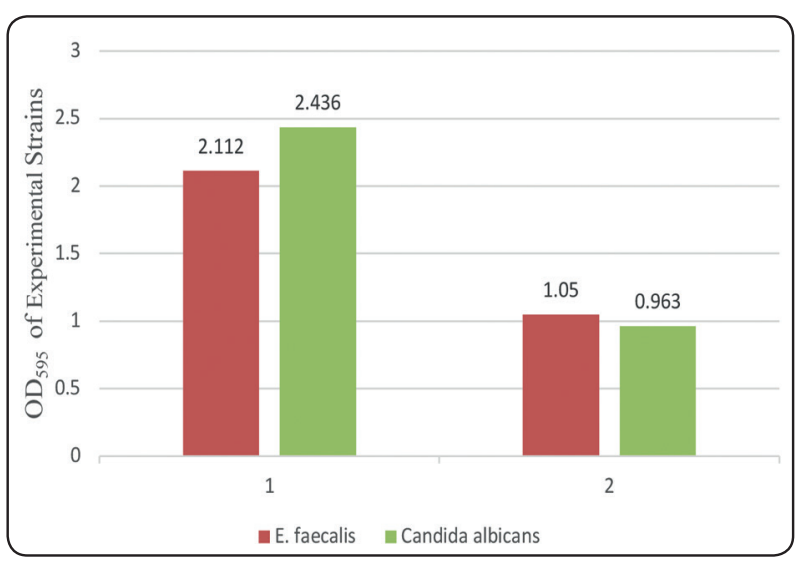

Fig. (4) Comparison of biofilm of each $\boldsymbol{E}$. faecalis and Candida albicans before and after medication by EndoVac

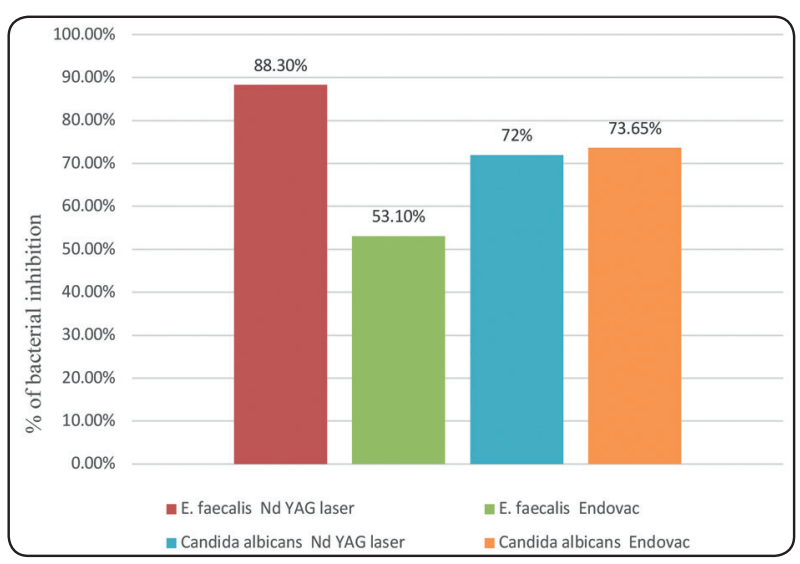

Fig. (5) Comparison of antibiofilm inhibition \% of each $\boldsymbol{E}$. faecalis and Candida albicans

\section{DISCUSSION}

Root canal irrigants main function, is to clean the root canal system during the shaping and enlargement procedure (Giardino et al., 2006) ${ }^{(9)}$. Many Previous experiments have demonstrated that the widely use of the conventional needle irrigation technique is not efficient anymore, especially at the apical third of the root canal (Torabinejad et al., 2003; Mancini et al.,2009). ${ }^{(10,11)}$

The advantages of mechanical instrumentation include reduced working time for root canal preparation. Moreover, the use of the ProTaper Next rotary system in this study with its rectangular cross-section design and asymmetric rotary motion improved the degree of canal-shaping. During rotation, the files create a mechanical wave of motion, which passes through the length of the working part of the instrument and reduces the contact between the instrument and dentin, resulting in enhanced debris removal and flexibility in the working part of the file ${ }^{(12)}$.

The yeast associated with persistent endodontic infections is well documented, suggesting suggesting Candida albicans may play an important role in endodontic clinical practice. Presumably, the persistence of this pathogen in the root canal may be due to its capability to survive in a hostile environment, such as in the root canal system after treatment and biofilm formation ${ }^{(13)}$, that's why was selected in this study.

A prolonged time of contamination with Candida albicans was used in order to increase intracanal biofilm formation and penetration into dentinal tubules in the form of hyphae and yeast ${ }^{(14)}$.

The other selected pathogen in this study is E. faecalis is a Gram-positive coccus, which is reported to be present in approximately $20-30 \%$ of primary infections and $67-77 \%$ of secondary infections ${ }^{(15)}$. It has a unique morphological and genetic composition, which enables it to form one of the most resistant biofilms that can resist the action of various antimicrobials used inside the root canal ${ }^{(16)}$. Various virulence factors have been isolated from $\boldsymbol{E}$. faecalis such as collagen binding proteins, aggregation substances, gelatinase etc., all which count for greater resistance and a very strong defense mechanism. Studies have shown that microbes respond differently to same irrigating solutions under different conditions i.e. planktonic and biofilm forms ${ }^{(17)}$. So in order to simulate the resistant biofilm conditions, in the present study E. faecalis biofilm was formed by incubating the colonies for 3 weeks at $37^{\circ} \mathrm{C}$ and in order to ensure the viability of the bacteria, fresh broth was added 
every alternate day so that no bacteria died of starvation. An important concept that has emerged over recent years was used in this study, which is the use of active physical methods for agitating the irrigating solution to improve its penetration within areas that are not reached by endodontic instruments and to accelerate the chemical actions of this alkaline fluid against planktonic microorganisms, biofilms, and soft tissue remnants and smear layers ${ }^{(18)}$. Among various lasers available, Nd: YAG laser is probably one of the most effective lasers for disinfection of root canal infected with $\boldsymbol{E}$. faecalis $^{(19)}$. 5 seconds resting period between each activation as recommended by Gutknechet et al. was used to lower the thermal effects and to diminish the potentially hazardous effect in periodontal tissue ${ }^{(20)}$. Regarding the antimicrobial efficacy of the two therapeutic protocols tested against Candida albicans \& $\boldsymbol{E}$. faecalis, all treatments were able to significantly reduce the numbers of this microorganism despite of the high initial bacterial levels. The higher efficacy of Nd:YAG laser than EndoVac can be attributed to the deep dentinal tubule penetration by $\mathrm{Nd}$ : YAG laser. Evidence suggests that lasers can penetrate to depths grater then $400 \mu$ inside the dentinal tubules and cause the killing of bacteria in these greater depths ${ }^{(21)}$. As well as the ability of the laser disinfection to inactivate any microorganisms that persist after irrigation routines have been completed as stated in previous work by Da Mota et al ${ }^{(22)}$. Moreover, Lasers apart from causing bactericidal effect also cause occlusion of the dentinal tubules and thereby closing all the avenues of bacterial reinfection ${ }^{(23)}$. EndoVac has the greatest advantage of delivering the irrigating solution to the WL with minimal risk of periapical extrusion, representing a safe method of irrigation/aspiration (24). this irrigation system was also found to be effective in eliminating the bacteria from the root canals in this study, but not as effective as the laser disinfection. Although the present study was conducted with standard protocols and guidelines but even then, it has certain limitations. Major limitation of the following study was that it was not entirely an In vivo study. Although every possible step was taken to create natural simulating conditions but even then, the real dynamism of purely in vivo conditions can never be achieved. Secondly, the antimicrobial effects achieved with various groups in the present study were obtained in In vitro conditions. On the other hand, the advantages of an In vitro study are the ability to ensure uniformity and control of variables. In this study, the apex of teeth was sealed with wax to simulate in vivo conditions such as gas entrapment in the root canal and periodontal ligament (25). The result of the present study is in accordance with the study done by Siu and Baumgartner, Mitchell et al., who reported that the EndoVac System is safer and is more effective in cleaning the root canal especially in the apical third ${ }^{(26)}$. And although of these facts and the significant reduction of the bacterial load with the EndoVac use, it is just a mechanical aid in irrigation and does not have any antibacterial properties by itself like lasers. Another study also showed the same result by (de Gregorio et al., 2010). This previous study reported that EndoVac had limited activation of the irrigant into lateral canals but reached the working length in the entire root canal successfully ${ }^{(27)}$. Result was not consistent with the study done by Hockett et al., which concluded that the EndoVac had the ability to remove bacteria more effectively from root canals than the tested irrigation system ${ }^{(28)}$. Conflicting data on the antimicrobial efficacy of the EndoVac system versus laser irrigation may be explained by critical methodological differences amongst studies, such as the volume, concentration and type of the irrigant solution. In the present study, care was taken regarding the use of a standard irrigant $(\mathrm{NaOCl}$ $5.25 \%)$ and of the same volume $(2 \mathrm{ml})$ for all groups. Also, the selection of the target microorganisms may partially account for these distinct results. 


\section{CONCLUSION}

Effective irrigant delivery is an essential prerequisite for successful endodontic treatment. In this study, laser group resulted in significantly higher antimicrobial effects compared with the EndoVac group when used in conjunction with sodium hypochlorite. Laser assisted irrigation technique for the disinfection of the root canal is a promising method for irrigation activation. However, further studies are required along with other irrigating solutions to determine an ideal irrigating regimen in endodontics.

\section{REFERENCES}

1. Block SS. Peroxygen compounds. In: Block SS, editor. Disinfection, Sterilisation and Preservation. 4th edn. Philadelphia PA: Lea \& Ferbiger; 1991.pp. 167-181.

2. Siqueria JF, Junior, Machado AG, Silviera RM, Lopes HP, de Uzeda M. Evaluation of the effectiveness of sodium hypochlorite used with three irrigation methods in the elimination of Enterococcus faecalis from the root canal in vitro. Int Endodont J. 1997;30:279-282

3. Steinberg D, Heling I, Daniel I, Ginsburg I. Antibacterial synergistic effect of chlorhexidine and hydrogen peroxide against Streptococcus sobrinus, Streptococcus faecalis, Staphylococcus aureus. J Oral Rehab. 1999;26:151-152

4. Molina B, Glickman G, Vandrangi P, Khakpour M. Evaluation of root canal debridement of human molars using the GentleWave System. J Endod. 2015;10:1701-1705

5. Daga P, Asrani H, Farista S, Mishra P. Comparative Evaluation of Antimicrobial Efficacy of Neem, Miswak, Propolis, and Sodium Hypochlorite against Enterococcus faecalis using EndoVac. Int J Prosthodont Restor Dent. 2017;7(2):60-65. doi:10.5005/jp-journals-10019-1178.

6. de Miranda RG, Colombo APV, Gusman HDS. Antimicrobial efficacy of the EndoVac system plus PDT against intracanal Candida albicans: an ex vivo study. Braz Oral Res. 2015;29(1):S1806-308. doi:10.1590/18073107BOR-2015.vol29.0129

7. Clinics D, Prospects D, Article O. Evaluation of Antimicrobial Effects of Different Concentrations of Triple Antibiotic Paste on Mature Biofilm of. 2015;9(3):05. doi:10.15171/joddd.2015.027
8. Parente JM, Loushine RJ, Susin L, Gu L, Looney SW, Weller RN, et al. Root canal debridement using manual dynamic agitation or the EndoVac for final irrigation in a closed system and an open system. Int Endod J. 2010 Nov; 43(11): 1001-12. doi: 10.1111/j.1365-2591.2010.01755.x

9. Giardino L, Ambu E, Becce C, Rimondini L, Morra M. 2006. Surface tension comparison of four common root canal irrigants and two new irrigants containing antibiotic. J Endod 32:1091-1093.

10. Torabinejad M, Cho Y, Khademi AA, Bakland LK, Shabahang S. 2003. The effect of various concentrations of sodium hypochlorite on the ability of MTAD to remove the smear layer. J Endod 29:233-239.

11. Mancini M, Armellin E, Casaglia A, Cerroni L, Cianconi L. 2009. A comparative study of smear layer removal and erosion in apical intraradicular dentine with three irrigating solutions: a scanning electron microscopy evaluation. J Endod 35: 900-903.

12. Soligo LT, Lodi E, Farina AP, Souza MA, Vidal C de MP, Cecchin D. Antibacterial efficacy of synthetic and naturalderived novel endodontic irrigant solutions. Braz Dent J. 2018;29(5):459-464. doi:10.1590/0103-6440201802172

13. Siqueira JF, Rôças IN, Ricucci D. Biofilms in endodontic infection. Endod Top. 2010;22:33-49.

14. Barbosa-Ribeiro M, De-Jesus-Soares A, Zaia AA, Ferraz CC, Almeida JF, Gomes BP. Antimicrobial susceptibility and characterization of virulence genes of Enterococcus faecalis isolates from teeth with failure of the endodontic treatment. J Endod. 2016;42:1022-8.

15. Rocas I, Siqueirajr J, Santos K. Association of Enterococcus faecalis With Different Forms of Periradicular Diseases. J Endod. 2004;30:315-20.

16. Dunavant TR, Regan JD, Glickman GN, Solomon ES, Honeyman AL. Comparative evaluation of endodontic irrigants against Enterococcus faecalis biofilms. J Endod. 2006;32:527-31.

17. Abdullah M,Ng Y-L, Gulabivala K, Moles DR, Spratt DA. Susceptibilties of two Enterococcus faecalis phenotypes to root canal medications. J Endod. 2005;31:30-6.

18. Walsh LJ, George R.Activation of Alkaline Irrigation Fluids in Endodontics. Materials (Basel). 2017;10(10):1214. Published 2017 Oct 23. doi:10.3390/ma10101214

19. Moritz A, Schoop U, Goharkhay K, Jakolitsch S, Kluger W, Wernisch J, et al. The bactericidal effect of Nd: YAG, Ho: 
YAG, and Er: YAG laser irradiation in the root canal: an in vitro comparison. J Clin Laser Med Surg. 1999;17:161-4.

20. Gutknecht N, Moritz A, Conrads G, Sievert T, Lampert F. Bactericidal effect of the Nd: YAG laser in in vitro root canals. J Clin Laser Med Surg. 1996;14:77-80

21. Stojicic S, Amorim H, Shen Y, Haapasalo M. Ex vivo killing of Enterococcus faecalis and mixed plaque bacteria in planktonic and biofilm culture by modified photoactivated disinfection. Int Endod J. 2013;46:649-59.

22. Da Mota A.C., Gonçalves M.L., Bortoletto C., Olivan S.R., Salgueiro M., Godoy C., Altavista O.M., Pinto M.M., Horliana A.C., Motta L.J., et al. Evaluation of the Effectiveness of Photodynamic Therapy for the Endodontic Treatment of Primary Teeth: Study Protocol for a Randomized Controlled Clinical Trial. Trials. 2015;16:551. doi: 10.1186/s13063-015-1086-2.

23. Moritz A, Schoop U, Goharkhay K, Jakolitsch S, Kluger W, Wernisch J. The bactericidal effect of Nd: YAG, Ho: YAG, and Er: YAG laser irradiation in the root canal: an in vitro comparison. J Clin Laser Med Surg. 1999;17:161-4

24. Nielsen BA, Baumgartner JC.Comparison of the EndoVac system to needle irrigation of root canals. J Endod 2007; 33:611-5.
25. Mancini M, Cerroni L, Iorio L, Armellin E, Cianconi L. Smear Layer Removal and Canal Cleanliness Using Different Irrigation Systems (EndoActivator, EndoVac, and Passive Ultrasonic Irrigation): Field Emission Scanning Electron Microscopic Evaluation in an In Vitro Study. J Endod. 2013; 39:1456-60.

26. Siu C, Baumgartner JC. Comparison of the debridement effi cacy of the EndoVac irrigation system and conventional needle root canal irrigation in vivo. J Endod 2010;36:17825. 19. Mitchell RP, Yang SE, Baumgartner JC. Comparison of apical extrusion of $\mathrm{NaOCl}$ using the EndoVac or needle irrigation of root canals. J Endod 2010;36:338-41.

27. De Gregorio C., Estevez R., Cisneros R., Paranjpe A., Cohenca N. Efficacy of different irrigation and activation systems on the penetration of sodium hypochlorite into simulated lateral canals and up to working length: An in vitro study. (2010) Journal of Endodontics, 36 (7) ,pp. $1216-1221$

28. Hockê̂ , JL, Dommisch, JK, Johnson, JD, Cohenca, N. Antimicrobial effi cacy of two irrigation techniques in tapered and nontapered canal preparations: An in vitro study. J Endod 2008;34:1374-7. 